\title{
Testing Metaphorical Educational FPS Games
}

\author{
John R. Rankin, Sandra Sampayo Vargas, and Paul F. Taylor \\ ACRI Games Technology Laboratory, Department of Computer Science and Computer Engineering, \\ La Trobe University, Bundoora, Victoria 3086, Australia \\ Correspondence should be addressed to Sandra Sampayo Vargas, ssampayovargas@students.latrobe.edu.au
}

Received 1 September 2008; Revised 5 March 2009; Accepted 19 May 2009

Recommended by Narendra Chaudhari

It is widely recognized that there is value in making use of modern Games Technology in Serious Games for educational purposes in the classroom and yet tools that enable teachers to construct such Educational Serious Games (ESGs) with minimal programming, artistic, or GT skills are not yet widely available. In this paper we investigate the feasibility of employing the FPS game genre for teaching purposes in the classroom. This is done by starting with a typical FPS game and constructing metaphorical correspondences with the desired ESG category. This mapping highlights the mentality level of FPS games and what it would take to modify them towards the level for real knowledge acquisition as in ESGs. By changing the game world rules to correspond with a classroom study area, we create a metaphorical educational FPS game. In this paper we describe two metaphorical educational FPS games and report on preliminary testing of their use in education. If testing of these metaphorical educational FPS games indicates that they would be beneficial in school classes then we intend to pursue the design of software tools and tutorials to enable teachers to develop their own metaphorical educational FPS games in two months or less.

Copyright ( 2009 John R. Rankin et al. This is an open access article distributed under the Creative Commons Attribution License, which permits unrestricted use, distribution, and reproduction in any medium, provided the original work is properly cited.

\section{Introduction}

Commensurate with the great improvements in CPU speed and GPU capabilities, computer games, and the Games Technology support software have advanced markedly in the last decade. The impact of games and this new technology is widespread amongst the next generation to the extent that now most children and school pupils play video games for amusement and recreation in their free time. When their teachers see how enthusiastic and involved their pupils are in the new technology and how less interested many of them are with the traditional school teaching methodologies, the teachers have raised the question of whether this new technology could also be employed productively for teaching purposes within the classroom. The use of GT for purposes other than pure entertainment gave rise to the domain of Serious Games (SGs) $[1,2]$ and the particular application of GT for educational purposes gave rise to the subdomain of SGs called Educational Serious Games (ESGs) [3, 4].

Nevertheless within the world of computer games, SGs represent only a small fraction of all video games, and ESGs are but a small fraction of SGs. Thus the world of video games is dominated by non-Serious Games-the so-called casual games [5]. The commercially successful SGs are small in number and very high in development cost and this raises the question of why there is currently a lack of commercial value in general purpose SGs [6]. The main development emphasis has been on casual games, and correspondingly, the available game development tools have been predominantly by far in the casual game market. The emphasis on casual games has also resulted in a lack of available tools for those game designers wanting to make SGs or ESGs [7].

In our research we have been investigating what tools are particularly appropriate to the development of SGs and finding out what is needed in SG tools beyond the tools currently available for casual games. We further narrowed the focus of our researches to consideration of just ESGs and in particular the development of ESGs for the classroom by teachers who have no skills or training in games technology programming, in digital artwork, 3D modeling, or animation. The Teacher's Dilemma [8] is what software tools would a teacher need to rapidly create an ESG for his class in a two month time frame where the teacher has no games programming skills or digital artwork skills and a budget limited to no more than 
TABLE 1: Metaphorical correspondences between FPSs and ESGs.

\begin{tabular}{|c|c|c|}
\hline \multicolumn{3}{|c|}{ Metaphorical correspondences } \\
\hline Feature & FPS game & Educational SGs \\
\hline $\begin{array}{l}\text { Kill rules for } \\
\text { each monster }\end{array}$ & $\begin{array}{l}\text { Are purely } \\
\text { arbitrary and } \\
\text { concocted by the } \\
\text { game designer }\end{array}$ & $\begin{array}{l}\text { Are a sequence of } \\
\text { actions to solve the } \\
\text { problem according to } \\
\text { how the teacher wants } \\
\text { them to solve it }\end{array}$ \\
\hline Difficulty & $\begin{array}{l}\text { Monsters shoot at } \\
\text { the player and the } \\
\text { player can lose a } \\
\text { life }\end{array}$ & $\begin{array}{l}\text { The player may take a } \\
\text { wrong action and } \\
\text { have to start the } \\
\text { problem solving again } \\
\text { from the start or exit } \\
\text { the room }\end{array}$ \\
\hline Feedback & $\begin{array}{l}\text { The monster is } \\
\text { killed and the } \\
\text { player gets a score } \\
\text { update and feels } \\
\text { pleased at } \\
\text { conquering it }\end{array}$ & $\begin{array}{l}\text { The player achieves } \\
\text { the solution and } \\
\text { records the observed } \\
\text { results in the } \\
\text { workbook }\end{array}$ \\
\hline $\begin{array}{l}\text { Weapons and } \\
\text { bullets }\end{array}$ & $\begin{array}{l}\text { Different weapons } \\
\text { have different } \\
\text { powers in killing } \\
\text { different monsters }\end{array}$ & $\begin{array}{l}\text { The player can choose } \\
\text { different actions or } \\
\text { steps to take in } \\
\text { solving the problem }\end{array}$ \\
\hline
\end{tabular}

a couple of hundred dollars? Such tools are not currently available to teachers at present though there is now a strong demand for them [9]. This paper describes a new kind of video game which we call a Metaphorical Educational First Person Shooter video game (MEFPS) which may assist in alleviating the Teacher's Dilemma, and this paper reports on the software development and testing of two games of this sort.

\section{Metaphorical Correspondences}

Typically an FPS game involves fantasy monsters, fantasy weapons, and a fantasy $3 \mathrm{D}$ world to be explored by the player [10]. In contrast ESGs use operable and realistic representations of the things relating to the subject area such as a chemistry laboratory with cupboards, test tubes, beakers, and other apparatus and chemicals in jars. It is very costly to create this level of realism by digital artwork and 3D modeling. The basic game features of FPS games though of fantasy rather than reality can however be used to metaphorically represent the real-world artifacts of ESGs thus making FPS features more meaningful in the game for the purpose of teaching an educational concept.

Rankin Vargos [11] showed that there can be metaphorical correspondences between FPS games and ESGs and showed what FPS extensions FPS tools must support in order to develop ESGs. In [11] the ChemLab Educational Serious Game was described and it was explained how this game could be represented with the use of merely FPS features. For this we will have to use metaphorical correspondences for each one of the features used in a basic FPS game. Table 1 lists the metaphorical correspondences between FPS game features and ESGs.

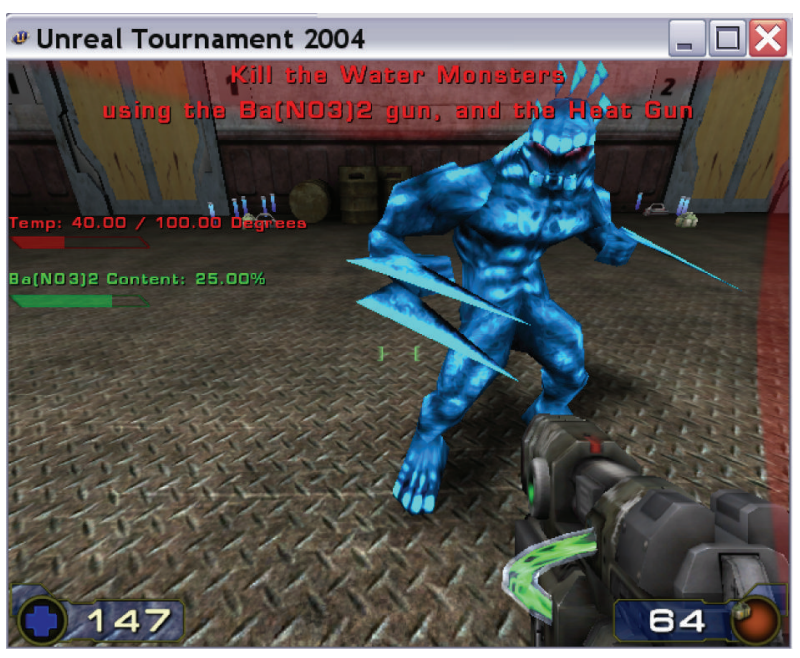

Figure 1: SolubilityFPS game.

\section{MEFPS Testing}

For testing the concept we created two video games under Unreal Tournament [12]. These games are the first prototypes of Metaphorical Educational FPS games. The first game is called SolubilityFPS. In this game the player starts in an almost empty warehouse with some ammunition and crates on the floor and four doors to other rooms along one side. The player is expected to enter each room where he will find an armed monster ready to shoot and kill him. The player already carries two fantasy rifle-like projectile weapons that he can swap between a green gun and a red gun. The green gun is used to represent metaphorically the collection of grams of the salt $\mathrm{Ba}\left(\mathrm{NO}_{3}\right)_{2}$ that will be added to the water which is represented by a monster. Shooting the blue monster with the green gun is metaphorically equivalent to adding 5 grams of the salt to the solution. The red gun is used to represent the temperature of the water. Each shot on the monster with the red gun represents heating the water by an amount of 5 degrees Centigrade. Once a monster is killed it represents reaching a point on the solubility curve for the salt $\mathrm{Ba}\left(\mathrm{NO}_{3}\right)_{2}$. There are 4 monsters in total giving 4 points on the curve that will help the player to draw the solubility curve of that particular salt in a workbook (see Table 2).

The HUD displays two bars: a red bar to represent the shots counted from the red gun (representing the water temperature) and a green bar representing a percentage figure which is the concentration level of the chemical in solution (see Figure 1). The player is provided with a workbook containing graph paper for drawing the solubility curve. The game has danger in that monsters aggressively shoot back at the player and if a door is open for too long a monster can escape from his room and continue pursuing the player. Doors open based on a proximity trigger, allowing the monsters to pursue the player. The monster pursuing and shooting at the player has the metaphorical correspondence of the challenge that the concept of solubility curves has to the students understanding. 
The second game is called ChemLab FPS. This game starts in a similar warehouse containing only ammunition and a few crates on the floor but now with 5 doors to rooms (four doors on the opposite side from where you start and one on the far side) and 2 empty beakers painted onto the HUD (see Figure 2). Again the player is expected to go into each room where armed monsters are located, and kill them. The metaphorical correspondences of this video game consist of representing the substances of water, $\mathrm{PbCl}_{2}$ and $\mathrm{Na}_{2} \mathrm{SO}_{4}$ with 3 different types of monsters (see Table 3 ). The monsters will have the color of the substance they metaphorically represent to easily recognize what substance is being collected every time that particular monster is killed. To finish the game the player has to collect $200 \mathrm{~mL}$ of water, $20 \mathrm{gms}$ of $\mathrm{Na}_{2} \mathrm{SO}_{4}$, and $10 \mathrm{gms}$ of $\mathrm{PbCl}_{2}$. All of these quantities appear in the HUD of the game and vary according the number of monsters killed. When all the right quantities have been collected the screen displays a large beaker with the combined solutions and the chemical reaction completed. The player will see the colour of the precipitant and its chemical formula is displayed on the HUD (see Figure 3). The player must record this information into his workbook answering the appropriate questions in that book.

To run the tests we arranged for university students of various ages to fill in an initial questionnaire to know before the student plays the game whether he plays video games or not and if he plays FPS games. Next the participants play the SolubilityFPS game and then fill in a second questionnaire on their impressions after playing. Subsequently the participants play the ChemLab FPS game and fill in a third questionnaire on their impressions of playing that game and whether they thought games like that would be useful for teaching in the classroom. The questionnaires given out after the SolubilityFPS and ChemLab FPS games contain the same ten questions: the first six questions using a Likert scale from 1 to 5 (where 1 represents Strongly Disagree and 5 represents Strongly Agree); the next three questions have one answer choice from five distinct options and the last question is of free format where the participants could write their own comments (see Table 4).

\section{Test Results}

The survey results were collated into a large table with a row per participant and a column per question indicating which answer each participant selected for each question. We found that the time for one participant to complete the experiment was between 20 and 30 minutes. Since we were limited to two machines for running the 2 games (which require the Unreal Tournament license), our initial surveys were limited due to time constraints to just 27 participants-21 men and 6 women with ages ranging from 19 to 62 and average age 26 . From this data we were able to draw some results (see Tables 5 and 6 ).

The survey results for both games were very similar. From the survey the average result is that the participants enjoyed both games ChemLab FPS (4.0 on the Likert scale) and SolubilityFPS (3.81 on the Likert scale). All responded

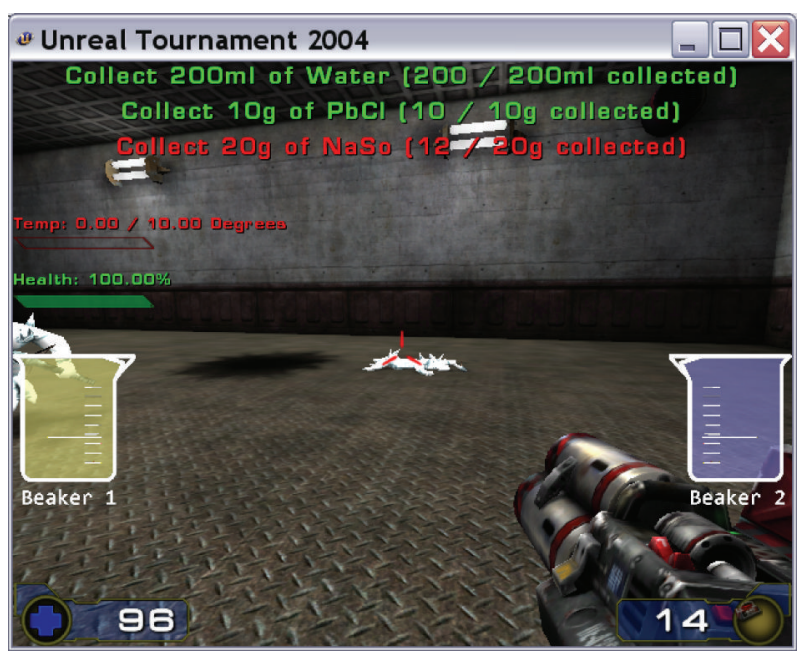

FIgURE 2: ChemLab FPS game-collecting $\mathrm{Na}_{2} \mathrm{SO}_{4}$ at killing the white monster.

TABLE 2: Metaphorical correspondences for SolubilityFPS.

\begin{tabular}{|c|c|}
\hline FPS Feature & SolubilityFPS \\
\hline Monsters & 100 grams of water. \\
\hline $\begin{array}{l}\text { Each accurate shot } \\
\text { with the green } \\
\text { weapon }\end{array}$ & $\begin{array}{l}5 \text { grams of the salt } \\
\mathrm{Ba}\left(\mathrm{NO}_{3}\right)_{2}\end{array}$ \\
\hline $\begin{array}{l}\text { Each accurate shot } \\
\text { with the red weapon }\end{array}$ & $\begin{array}{l}5 \text { centigrade degrees } \\
\text { of temperature }\end{array}$ \\
\hline
\end{tabular}

TABLE 3: Metaphorical correspondences for ChemLab FPS.

\begin{tabular}{ll}
\hline FPS Feature & ChemLab FPS \\
\hline $\begin{array}{l}\text { Every killed blue } \\
\text { monster of room } 2\end{array}$ & $30 \mathrm{ml}$ of water \\
$\begin{array}{l}\text { Every killed brown } \\
\text { monster of room } 1\end{array}$ & 5 grams of $\mathrm{PbCl}_{2}$ \\
$\begin{array}{l}\text { Every killed white } \\
\text { monster of room } 3\end{array}$ & 4 grams of $\mathrm{Na}_{2} \mathrm{SO}_{4}$ \\
\hline
\end{tabular}

that they would like to play the games again (3.52 on the Likert scale). All agree that both games are helpful for learning (for SolubilityFPS 3.59 and for ChemLab FPS 3.67). However, females reported uncertainty about whether the games helped them learn the topic (Likert scale 3.17 for SolubilityFPS and 3.33 for ChemLab FPS). Males answered that both games may be useful for basic lessons in natural sciences at the high school level but females reported uncertainty. In the game SolubilityFPS males liked the graphics the most and girls preferred the actions, and in the ChemLab FPS game all preferred the actions. The participants played both games each one for about 15 minutes on average but the females played the SolubilityFPS game for less than 10 minutes on average. Male participants answered that both games are easy to play and females reported uncertainty only in ChemLab FPS (Likert scale 2.83). From the survey we also found that males play fewer video games than girls. On average the participants play FPS video games regularly (i.e., about once 


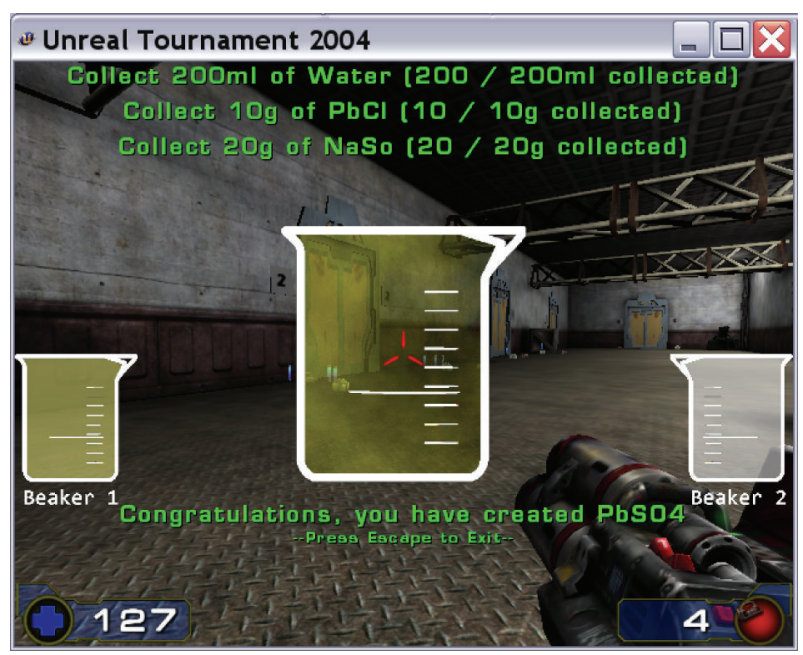

Figure 3: ChemLab FPS game final screen.

TABLE 4: List of questions after playing the game.

\begin{tabular}{|c|c|}
\hline No. & Questions \\
\hline 1 & Did you enjoy playing this game? \\
\hline 2 & Would you like to play this game again? \\
\hline 3 & $\begin{array}{l}\text { Is this game a helpful way for you to learn } \\
\text { solubility curves/chemical reactions? }\end{array}$ \\
\hline 4 & $\begin{array}{l}\text { Do you think you could improve your } \\
\text { skills at solving this sort of problem by } \\
\text { playing this game more than once? }\end{array}$ \\
\hline 5 & $\begin{array}{l}\text { Do you think that his kind of learning } \\
\text { approach will be useful for teaching basic } \\
\text { lessons at high school level? }\end{array}$ \\
\hline 6 & Did you find the game easy to play? \\
\hline 7 & $\begin{array}{l}\text { In which subjects would you think it } \\
\text { would be useful to use games like these to } \\
\text { help you to learn? }\end{array}$ \\
\hline 8 & $\begin{array}{l}\text { What did you like the most about the } \\
\text { game? }\end{array}$ \\
\hline 9 & For how long did you play the game? \\
\hline 10 & Free Comments. \\
\hline
\end{tabular}

a day). Finally we found that the participants have also played educational video games about once a week on average. The females were the category which although agreeing on the potential usefulness of the games in learning had consistently lower Likert scales of agreement than the males.

It was apparent from this survey that even though most of the participants were already familiar with FPS games and the use of computers, it was necessary to explain at the start of each test to each participant what the game was about, what they had to do in the game, and how to play the game. The written instructions were not as well understood by the participants as the personal explanation given by the organizers of the tests and most of the participants prefer to have the instructions and the background story within the game at the start of the game.
TABLE 5: List of mean answers for the SolubilityFPS game.

\begin{tabular}{lccc}
\hline & \multicolumn{3}{c}{ SolubilityFPS } \\
Question number & Mean answer \\
& Total & Males & Females \\
\hline 1 & 3.81 & 3.95 & 3.33 \\
2 & 3.52 & 3.57 & 3.33 \\
3 & 3.59 & 3.71 & 3.17 \\
4 & 3.56 & 3.52 & 3.67 \\
5 & 3.85 & 4.14 & 2.83 \\
6 & 4.33 & 4.52 & 3.67 \\
\hline
\end{tabular}

TABLE 6: List of mean answers for the ChemLab FPS game.

\begin{tabular}{lccc}
\hline & \multicolumn{3}{c}{ ChemLab FPS } \\
Question number & Total & Mean answer & Females \\
\hline 1 & 4.00 & 4.14 & 3.50 \\
2 & 3.52 & 3.71 & 2.83 \\
3 & 3.67 & 3.76 & 3.33 \\
4 & 3.30 & 3.29 & 3.33 \\
5 & 3.78 & 3.95 & 3.17 \\
6 & 3.81 & 4.10 & 2.83 \\
\hline
\end{tabular}

The comments collected in the survey questionnaires will be used in the future to improve the next version of these games. Additionally we need to point out that the game by itself was not intended to teach the concept of solubility curves or chemical reactions but rather the game was meant to be only part of the teacher's lesson. We envisioned that after playing the game the teacher would follow up with a standard lesson for teaching the specific concept, that is, immersed in the gameplay of the video game and that by that stage the students would be used to the steps needed to accomplish the classroom problem solving exercises. We therefore believe that tweaking the games according to the feedback of the participants and further testing is needed to decide whether games of this sort could be useful in high school classrooms.

\section{Conclusions}

We developed two Metaphorical Educational FPS games as Unreal Tournament 2004 mods-one to present the concept of solubility curves and the other to present the concept of a chemical reaction involving precipitation. Both games were designed for potential use in high school chemistry lessons. The games being simple mods of Unreal Tournament have the same look and feel of the commercial Unreal Tournament game that is popular, widely available, and recommended for ages 15 and up. Players of the Unreal Tournament game would immediately recognize the monsters, the gun types, the ammunition pickups, the wall textures, and so on. However as mods they are considerably cut down versions of the commercially available game with a much smaller game 
world, fewer monsters, and limited weapons to choose from. The games were developed by Games Technology students of La Trobe University within two weeks. We do not expect teachers to produce games like this so quickly. Before we proceed to develop tools and tutorials to enable a teacher to produce a game like this in under two months we had to test whether participants believed that these types of games could be beneficial for classroom teaching. Our surveys suggest that it could be worthwhile to develop tools and tutorials for teachers to develop metaphorical educational FPS games for their classes.

Rather than testing the games on school children in the classroom, our initial testing was with a more mature university student population since there is still a public perception that such FPS games could do some psychological harm to young players. The results of our initial testing say that university students think that these kinds of games may help high school students to learn basic concepts of chemistry in the classroom. The use of the workbooks while playing the game was successful and participants answered the questions in the workbook correctly. No participant in the survey dropped out of the experiment due to fear of the game or concerns of possible psychological harm.

We received considerable feedback on ways to improve the games from the participants and after these improvements are made in the near future perhaps the educational objectives might be better realized [13]. Researching the attraction and engagement many players receive from traditional FPS games, and trying to create a similar level of enjoyment within the ESG genre is also an area we wish to explore. To this end we will be testing the different levels of abstraction that can be applied to the educational content of ESGs and the resulting level of education achieved by players. Moreover, further on in the future we intend to develop realistic ESGs to try ESGs in contrast with Metaphorical Educational FPS games where the educational concepts will be more explicit in the game and the level of simulated violence decreased.

\section{Credits}

The games were developed by Austin Mason and Paul Taylor over a 2 week period on PCs.

\section{Acknowledgment}

This research was supported by La Trobe University Grant and CONACyT Scholarship from the Government of $\mathrm{Me}$ xico.

\section{References}

[1] D. Michael and S. Chen, Serious Games: Games that Educate, Train and Inform, Thomson, Boston, Mass, USA, 2006.

[2] W. L. Wong, C. Shen, L. Nocera, et al., "Serious video game effectiveness," in Proceedings of the 4th International Conference on Advances in Computer Entertainment Technology (ACE '07), vol. 203, pp. 49-55, Salzburg, Austria, June 2007.
[3] S. M. Fisch, "Making educational computer games "educational",' in Proceedings of th Conference on Interaction Design and Children, pp. 56-61, Boulder, Colo, USA, June 2005.

[4] S. Egenfeldt-Nielsen, "Practical barriers in using educational computer games," On the Horizon, vol. 12, no. 1, pp. 18-21, 2004.

[5] W. Tinney, "Behind the screens: the technology of casual game development," Casual Games Quarterly, vol. 1, no. 1, 2005.

[6] J. R. Rankin and S. Sampayo, "A survey of real-world applications of serious games technology," in Proceedings of the Simulation-Maximising Organisational Benefits (SimTect '08), pp. 305-311, Melbourne, Australia, May 2008.

[7] K. White, "Casual games get serious," Casual Games Quarterly, vol. 2, no. 3, 2007.

[8] J. R. Rankin and S. Sampayo, "Survey of development tools for low-end serious games," in Proceedings of the 5th International Conference on Information Technology and Applications (ICITA '08), pp. 462-466, Cairns, Australia, 2008.

[9] M. Prensky, "SLIDE SHOW: Give Us 21st Centry Tools," Marc Prensky.com- Talk delivered at the Dept of Education's NCLB eLearning Summit, August 2008, http://www.marcprensky .com/writing/Prensky\%20-\%2004-07-NCLB-post.ppt.

[10] V. Young, Programming a Multiplayer FPS in DirectX, Charles River Media, Boston, Mass, USA, 2005.

[11] J. R. Rankin and S. Sampayo, "FPS extensions modelling ESGs," in Proceedings of the 2nd International Conferences on Advances in Computer-Human Interactions (ACHI '09), pp. 152-155, Cancun, Mexico, February 2009.

[12] Unreal Tournament 2004, March 2009, http://www .unrealtournament2004.com/ut2004/index.html.

[13] J. R. Rankin and S. Sampayo, "The educational value of metaphorical FPS games," in Proceedings of the Computer Games, Multimedia \& Allied Technology conference (CGAT'09), Singapore, May 2009. 

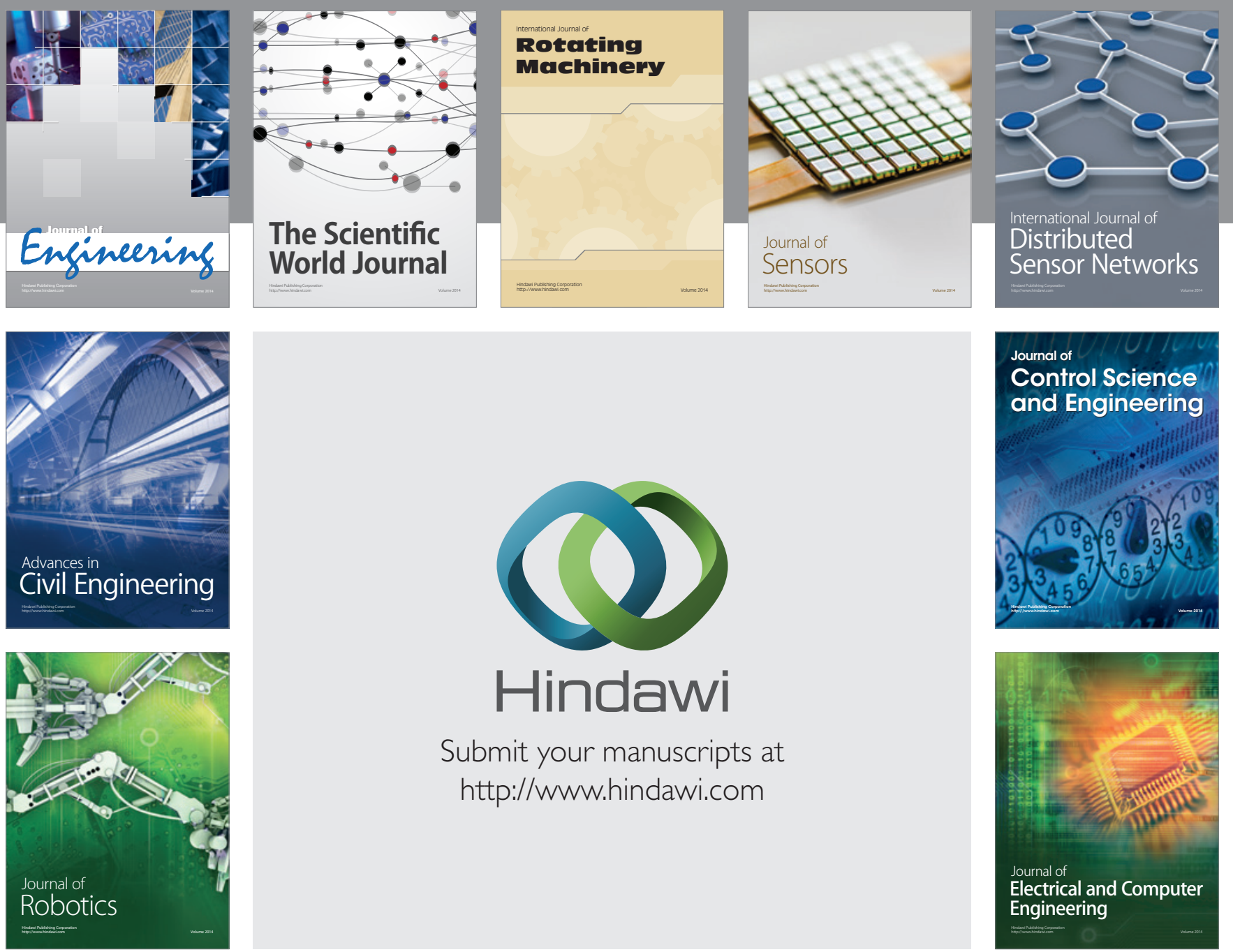

Submit your manuscripts at

http://www.hindawi.com
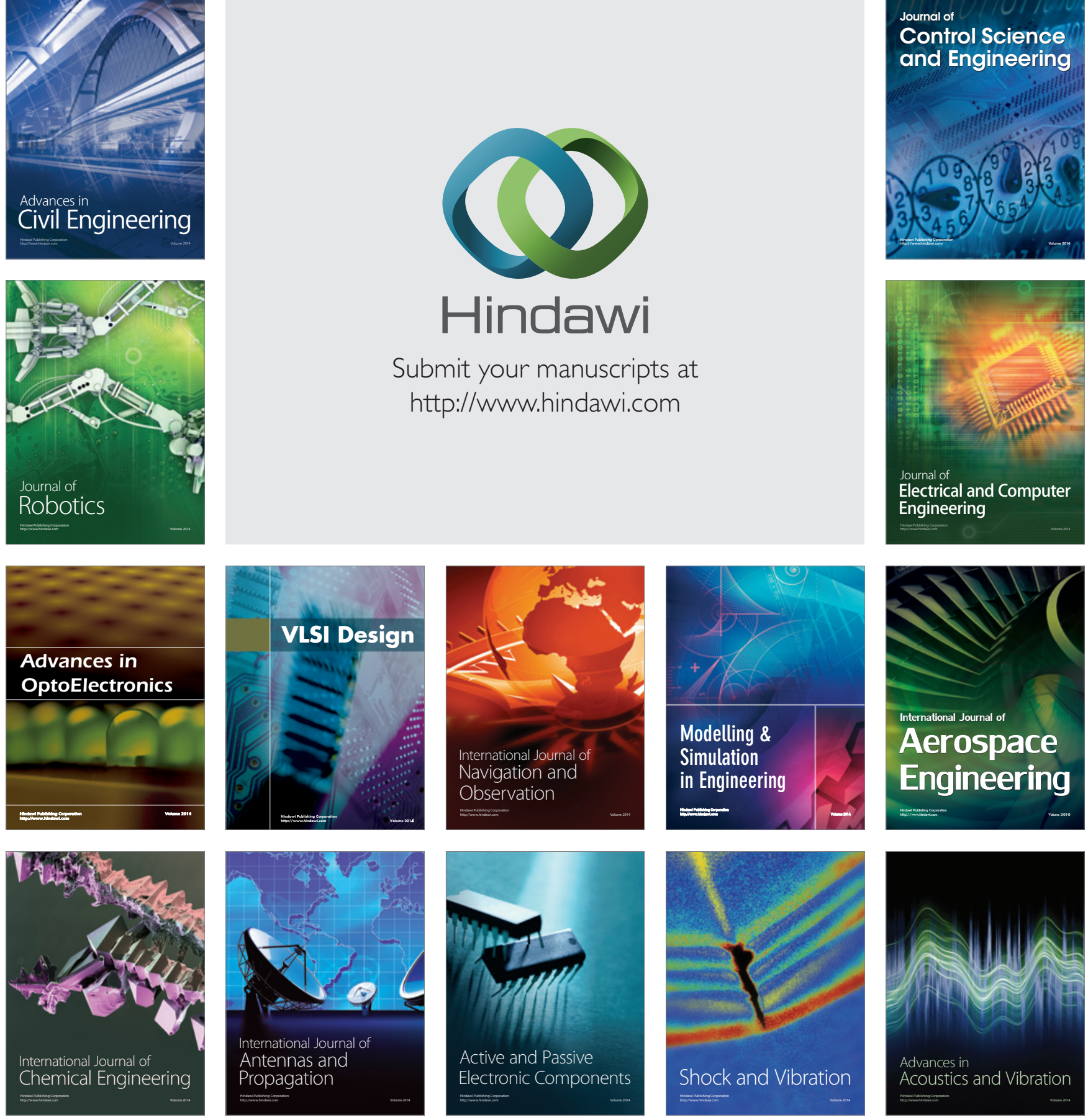